\title{
Pattern of adverse drug reactions reported at a tertiary care teaching hospital in northern India
}

\author{
Arpita Singh $^{1}$, Atul Jain ${ }^{1 *}$, Maneesh Soni ${ }^{2}$, Pooja Shukla ${ }^{1}$, \\ Joonmoni Lahon ${ }^{1}$, Ajay Kumar Verma ${ }^{3}$
}

\begin{abstract}
${ }^{1}$ Department of Pharmacology, Dr. Ram Manohar Lohia Institute of Medical Sciences, Lucknow, Uttar Pradesh, India ${ }^{2} \mathrm{Pv}$ Associate, NCC-PvPI, IPC, Ghaziabad, Uttar Pradesh, India

${ }^{3}$ Department of Respiratory Medicine, King George's Medical University, Lucknow, Uttar Pradesh, India
\end{abstract}

Received: 28 January 2020

Revised: 09 March 2020

Accepted: 11 March 2020

\section{*Correspondence:}

Dr. Atul Jain,

Email drjainatul1@gmail.com

Copyright: (C) the author(s), publisher and licensee Medip Academy. This is an open-access article distributed under the terms of the Creative Commons Attribution Non-Commercial License, which permits unrestricted non-commercial use, distribution, and reproduction in any medium, provided the original work is properly cited.

\begin{abstract}
Background: Adverse drug reactions (ADRs) are among the leading cause of morbidity and mortality in hospital setup. This study was conducted with the aim of understanding the pattern and occurrence of ADRs to minimize their risk and safeguard public health.

Methods: This study is a retrospective analysis of pattern of ADRs reported at ADR monitoring centre (AMC) in a tertiary care hospital. A total of 207 spontaneous ADR reports collected over a period of 18 months were analysed for pattern and type of reactions, demographic profile of patients, organ system affected by ADRs, causative drugs, route of drug administration, severity of reaction, their outcome, management and causality assessment.

Results: Most common age group affected by ADRs was 41-50 years with almost equal involvement of male and female gender. Cutaneous reactions involving skin like rashes and itching were most common ADRs. The most common causative drug for ADRs were antimicrobials agents like Penicillin and Cephalosporin group of antibiotics. Orally administered drugs were most commonly involved in causing ADRs. Most of the ADRs belonged to Type A category, were non-serious and moderate in severity. Most of the patients recovered from the ADRs on stopping the suspected drug. On assessing the causality, most of the ADRs were probable with the suspected drugs.

Conclusions: Most of the patients recover from ADRs with appropriate and timely intervention, but it is important to understand the pattern and occurrence of ADRs for patient safety and this is possible only with an effective and robust pharmacovigilance system.
\end{abstract}

Keywords: Adverse drug reaction, AMC, Causality assessment, Pharmacovigilance

\section{INTRODUCTION}

Medicines are intended for treatment and better outcome but still there are possibilities of occurrence of adverse drug reactions. Adverse drug reaction is defined as "a response to a medicine which is noxious and unintended, and which occurs at doses normally used in man for the prophylaxis, diagnosis or therapy of the disease or for the modifications of physiological function."1 According to various studies, adverse drug reactions are one of the leading causes of morbidity and it accounts for a significant number of hospital admissions in India and worldwide. A study in India reported overall incidence of 9.8\% ADRs including 3.4\% of total hospital admissions and $3.7 \%$ ADRs developed during hospital stay. ${ }^{2}$ Hence, understanding the benefit and risk of drug therapy is necessary for which an effective nationwide pharmacovigilance system is essential. 
Pharmacovigilance (PV) is defined by the WHO as "the science and activities relating to the detection, assessment, understanding and prevention of adverse effects or any other drug-related problem". 3 Pharmacovigilance Programme of India (PvPI) was operationalized in July, 2010 by Ministry of Health and Family Welfare, Government of India. The AIIMS, New Delhi was established as National Coordination Centre (NCC) for PvPI. 22 ADR Monitoring Centres (AMCs) had been set up under this programme. In 2011, NCC was shifted to Indian Pharmacopoeia Commission (IPC), Ghaziabad. During last 7 years PvPI has collaborated with several national health programmes and research institutions and the number of AMCs (ADR Monitoring Centres) has increased to more than 250. In 2017, the Pharmacovigilance Programme of India (PvPI)- Indian Pharmacopoeia Commission (IPC), in Ghaziabad, India, became a WHO Collaborating Centre. ${ }^{4}$ Since there exist considerable social and economic consequences of adverse drug reactions, there is a need to engage healthcare professionals and the public at large, in a wellstructured programme. The vision of PvPI is to improve patient safety and welfare in Indian population by monitoring drug safety and thereby reducing the risk associated with use of medicines. ${ }^{5}$ Our AMC (adverse drug reaction monitoring centre) is designated under PvPI and is working for the safety and welfare of patients by early detection, reporting and monitoring of ADR in hospital setup and by providing its prompt and appropriate management. This is a retrospective study done to analyze the ADR reported at our AMC to know the type and pattern of ADR reported, demographic profile of patients, organ system involved, causative drugs, severity, outcome, management and causality assessment, in view of improving health safety of patients.

\section{METHODS}

All the ADR reported in the study duration were included in this study. The ADRs were collected from various departments at our AMC, on the "suspected adverse drug reaction reporting form" from the health care professionals, as prescribed by IPC. ${ }^{6}$ Causality for ADRs were assessed according to WHO Uppsala Monitoring Centre (UMC) Causality Assessment Criteria. ${ }^{7}$ The Pv associate at our AMC then uploads the reports in Vigiflow software and send it to NCC, IPC Ghaziabad which is further send after analysis to Uppsala Monitoring Centre, Sweden for maintaining ADR database, further analysis and signal detection. ${ }^{8}$

A total of 207 suspected ADR reports were received from various department at our AMC from September 2017 to February 2019. These reports were analysed retrospectively for the demographic profile of patients, type and pattern of ADRs, causative drugs, severity of ADRs, their outcome, management and causality assessment.
This study was done after getting ethical clearance from the Institutional Ethics Committee, strict confidentiality was maintained about the particulars of involved patients during the study. Data analysis was done using descriptive statistical analysis. ${ }^{9}$

\section{RESULTS}

The age group most commonly involved with ADRs was in the range of $41-50$ years $(n=44,21.25 \%)$ followed by 51-60 years $(n=39,18.84 \%)$ and then $21-30$ years $(n=38$, $18.35 \%)$. The gender distribution was almost equal for both males $(n=104,50.25 \%)$ and females $(n=103$, 49.75\%) as shown in Figures 1 and 2.

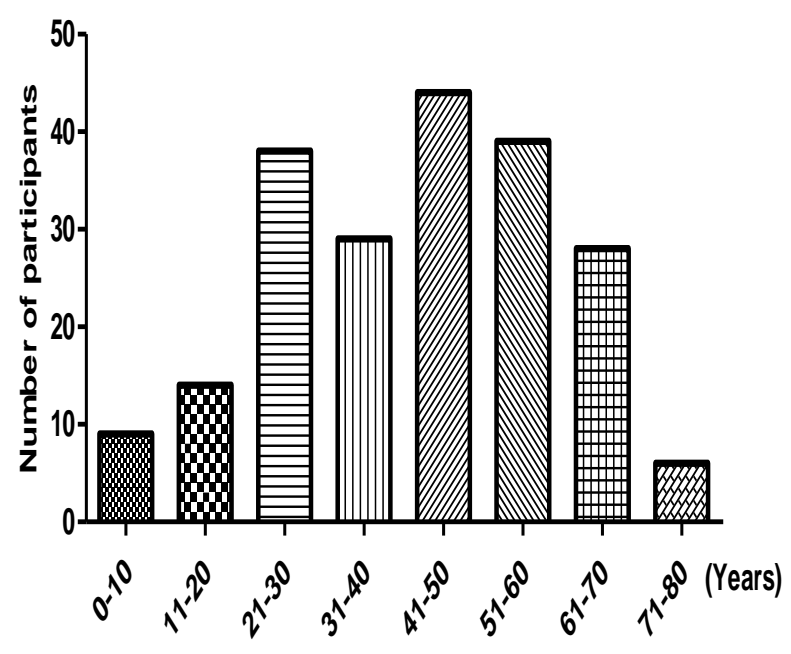

Figure 1: Age distribution.

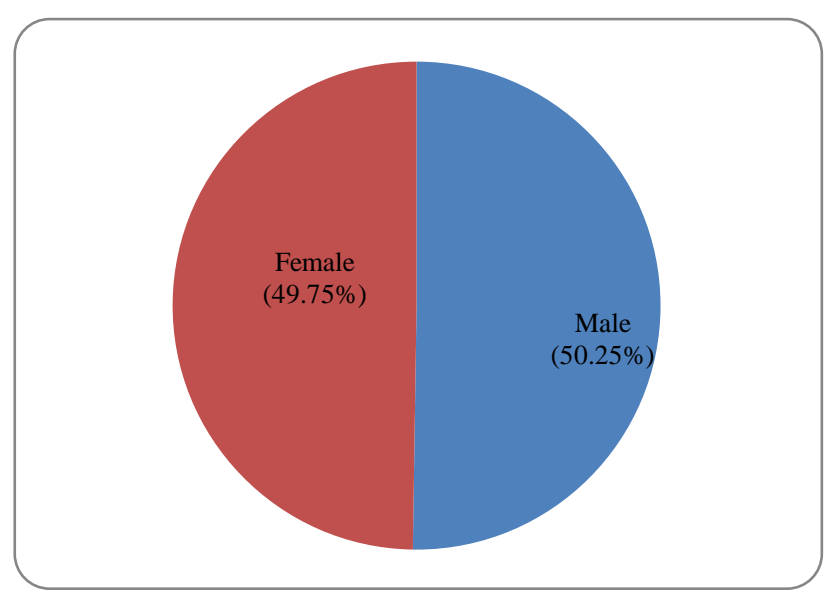

Figure 2: Gender distribution.

Cutaneous ADRs ( $\mathrm{n}=92,44.44 \%)$ involving skin like rashes and itching were the most common ADRs reported by various departments. This is followed by generalized ADRs $(n=52,25.12 \%)$ like whole body discomfort, chills and rigors, and then gastrointestinal ADRs $(n=20,9.66 \%)$ like vomiting, abdominal pain, and diarrhoea (Table 1). 
The drugs involved most commonly with ADRs were Antimicrobial agents $(n=62,29.95 \%)$ belonging to Penicillin and Cephalosporin group, followed by drugs acting on central nervous system $(n=41,19.80 \%)$ like
Antiepileptics and Antidepressants which is then followed by Anti-cancer drugs $(n=24,11.59 \%)$ like Paclitaxel and Rituximab (Table 2).

Table 1: Pattern of ADRs involving different organ systems.

\begin{tabular}{|c|c|}
\hline ADRs & Value \\
\hline Cutaneous & $(44.44 \%)$ \\
\hline Skin rashes & 61 \\
\hline Itching & 16 \\
\hline Skin inflammation & 7 \\
\hline Hyperpigmentation & 2 \\
\hline Exfoliation & 2 \\
\hline Ecchymotic patches & 1 \\
\hline Thrombophlebitis & 1 \\
\hline Stevens Johnsons syndrome & 1 \\
\hline Pimples on face & 1 \\
\hline Generalised ADR & $52(25.12 \%)$ \\
\hline Chills and rigors & 16 \\
\hline Body discomfort & 15 \\
\hline Generalised swelling & 9 \\
\hline Dizziness & 4 \\
\hline Weakness & 3 \\
\hline Lymphadenopathy & 1 \\
\hline Muscle cramps & 1 \\
\hline Generalised inflammation & 1 \\
\hline Giddiness & 1 \\
\hline Generalised oedema & 1 \\
\hline Gastrointestinal ADRs & $20(9.66 \%)$ \\
\hline Vomiting & 5 \\
\hline Abdominal pain & 5 \\
\hline Diarrhoea & 4 \\
\hline Hepatitis & 2 \\
\hline Nausea & 1 \\
\hline Loss of appetite & 1 \\
\hline Difficulty in eating and drinking & 1 \\
\hline Gastritis & 1 \\
\hline Central nervous system ADRs & $13(6.28 \%)$ \\
\hline Sleepiness & 4 \\
\hline Sedation & 2 \\
\hline Tingling & 2 \\
\hline Headache & 2 \\
\hline Tremors & 1 \\
\hline Stiffness & 1 \\
\hline Cardiovascular ADRs & $12(5.79 \%)$ \\
\hline Palpitation & 11 \\
\hline Hypertension & 1 \\
\hline Respiratory system ADRs & $10(4.83 \%)$ \\
\hline Dyspnoea & 7 \\
\hline Chest pain & 2 \\
\hline Hematological ADRs & $4(1.93 \%)$ \\
\hline Thrombocytopenia & 3 \\
\hline Pancytopenia & 1 \\
\hline Renal system ADRs- & $3(1.44 \%)$ \\
\hline Hyperuricaemia & 2 \\
\hline Uremia & 1 \\
\hline Endocrine system ADRs & $1(0.48 \%)$ \\
\hline Gynaecomastia & 1 \\
\hline
\end{tabular}


Table 2: Suspected drugs causing ADRs.

\begin{tabular}{|c|c|}
\hline ADRs & Value \\
\hline Antimicrobial agents (antibiotics) & $62(29.95 \%)$ \\
\hline Ceftriaxone & 8 \\
\hline Piperacillin+tazobactum & 7 \\
\hline Ciprofloxacin & 6 \\
\hline Isoniazid+rifampicin & 5 \\
\hline Amoxicillin+clavulanic acid & 4 \\
\hline Pyrazinamide & 3 \\
\hline Aztreonam & 2 \\
\hline Tigecycline & 2 \\
\hline Meropenem & 2 \\
\hline Colistimethate sodium (Colistin) & 2 \\
\hline Vancomycin & 2 \\
\hline Teicoplanin & 2 \\
\hline Linezolid & 2 \\
\hline Polymyxin B & 2 \\
\hline Cefuroxime & 1 \\
\hline Clarithromycin & 1 \\
\hline Lamivudine+tenofovir+efavirenz & 1 \\
\hline Cefoperazone+sulbactam & 1 \\
\hline Cefixime & 1 \\
\hline Amphotericin B & 1 \\
\hline Ticarcillin+clavulanic acid & 1 \\
\hline Imipenem+cilastatin & 1 \\
\hline Moxifloxacin & 1 \\
\hline Fluconazole & 1 \\
\hline Penicillin G & 1 \\
\hline Voriconazole & 1 \\
\hline Rifampicin & 1 \\
\hline Drugs acting on central nervous system & $41(19.80 \%)$ \\
\hline Pregabalin & 6 \\
\hline Amitryptiline & 4 \\
\hline Valproic acid & 4 \\
\hline Gabapentine & 4 \\
\hline Notriptyline & 4 \\
\hline Oxcarbazepine & 3 \\
\hline Phenytoin & 3 \\
\hline Tramadol & 2 \\
\hline Duloxetine & 2 \\
\hline Levetiracetam & 2 \\
\hline Cinnarizine & 1 \\
\hline Topiramate & 1 \\
\hline Vilazodone & 1 \\
\hline Pyridostigmine & 1 \\
\hline Mirtazapine & 1 \\
\hline Buspirone & 1 \\
\hline Mannitol & 1 \\
\hline Chemotherapeutic agents (anti-cancer drugs) & $24(11.59 \%)$ \\
\hline Paclitaxel & 10 \\
\hline Rituximab & 5 \\
\hline Oxaliplatin & 3 \\
\hline 5-Fluoro uracil & 1 \\
\hline Carboplatin & 1 \\
\hline Docetaxel & 1 \\
\hline Etoposide & 1 \\
\hline Erlocip & 1 \\
\hline Gefitinib & 1 \\
\hline
\end{tabular}

Continued. 
ADRs

Nutritional supplements and electrolytes

Human albumin

$\mathrm{KCl}$

Celemin hepa

Normal Saline

Cobamamide

Pyridoxine

Evion

Folic acid

Vitamin D3

Ringer lactate

Cardiovascular drugs

Amlodipine

Metoprolol

Rosuvastatin

Telmisartan

Amiodarone

Enalapril

Carvedilol

Atenolol

Ivabradine

Gastrointestinal drugs

2

Domperidone

Ondansetrone

Metoclopramide

Bifilac

Raberprazole

Furazolidone

Dicyclomine

Metronidazole

Norfloxacin+tinidazole

Non-steroidal anti-inflammatory drugs

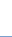

2

2

1

1

1

1 1

Etoricoxib

Indomethacin

Aceclofenac

Paracetamol

Aspirin

Endocrine system drugs

Levothyroxine

Ergocalciferol

Calcium carbonate

Dexamethasone

Canagliflozin

Megesterol

Metformin

Renal system drugs

4

4

2

1 1

1

1 1

Spironolactone+torasemide

Furosemide+amiloride

Alfuzosin hydrochloride

Haematological system drugs

Vitamin K (Phytomenadione)

Clopidogrel

Iron-Sucrose

Anti-histaminic drugs

2

2

2

1

1

1 1

Hydroxyzine

Monteleukast+fexofenadine

Levocetrizine

1 1

Vaccine 
According to Rawlins and Thompson classification $74.87 \%$ ADRs $(n=155)$ belonged to type A (augmented or predictable) category and $25.12 \%$ ADRs $(n=52)$ belonged to type B (bizarre/unpredictable) category (Figure 3). ${ }^{10}$

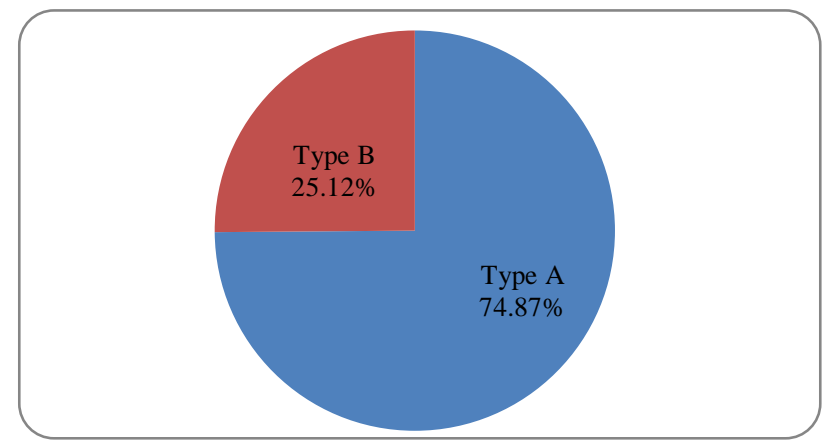

Figure 3: Type of ADRs.

Oral route of drug administration accounts for $57 \%$ $(\mathrm{n}=118)$ ADRs, I.V. route for $42.51 \%(\mathrm{n}=88)$ while I.M. route for only one $\mathrm{ADR}(\mathrm{n}=1,0.48 \%)$ out of total cases (Figure 4).

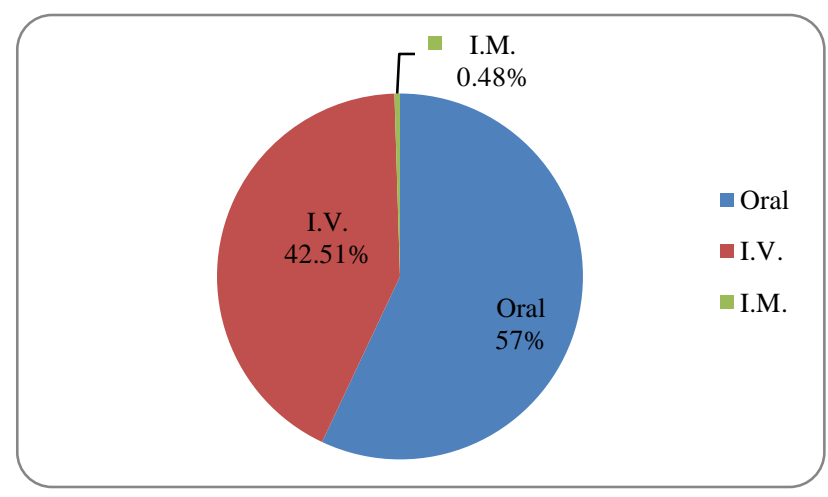

Figure 4: Route of drug administration.

For assessing the severity of ADRs, modified Hartwig and Siegel Scale was used. ${ }^{11}$ According to this scale, maximum ADRs belonged to moderate category $(n=111$, $53.62 \%)$, mild category ADRs were $43.96 \%(n=91)$ while only $2.41 \%$ ADRs $(\mathrm{n}=5)$ were severe (Figure 5$)$.

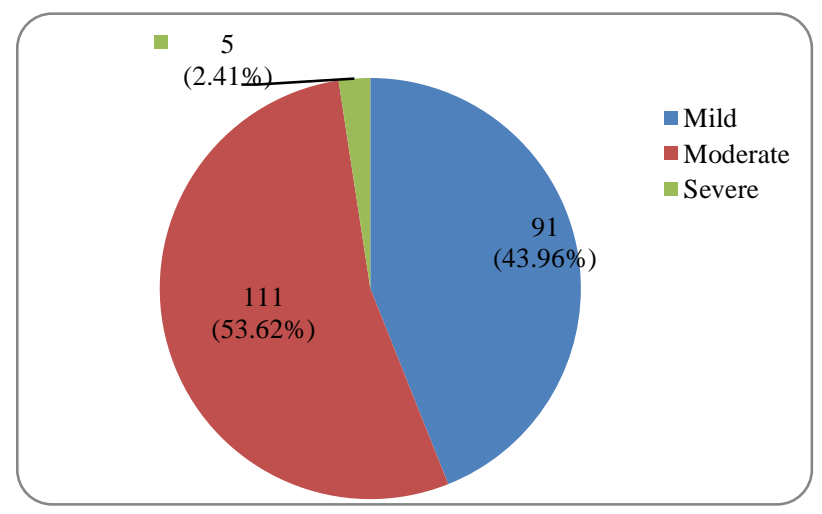

Figure 5: Severity of ADR.
The WHO-UMC Causality Assessment Criteria was used for assessing causality of ADRs. According to this criteria, maximum ADRs $(\mathrm{n}=195,94.20 \%)$ were probable $2.89 \%(n=6)$ were possible, $1.44 \%(n=3)$ were certain while $1.44 \%(n=3)$ were unlikely with the suspected drug (Figure 6).

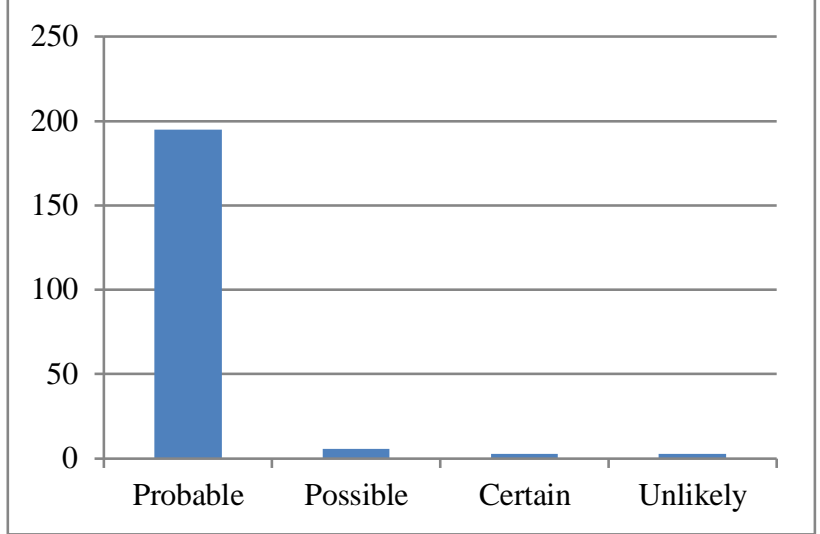

Figure 6: Causality assessment of ADRs.

Most of the ADRs (97.58\%, n=202) were non-serious while only $2.41 \%(n=5)$ were serious in nature. The patients who recovered from the ADR after taking appropriate steps like stopping the suspected drug were $59.90 \%(n=124)$, patients who did not recover at all were $39.61 \%(n=82)$ while $0.48 \%(n=1)$ one case was fatal which led to death of the patient.

Table 3: Seriousness, outcome, and management of ADRs.

\begin{tabular}{|lll|}
\hline & $\begin{array}{l}\text { Recovered: } 124 \\
(59.90 \%)\end{array}$ & $\begin{array}{l}\text { Suspected drugs } \\
\text { stopped: } 117 \\
(56.52 \%)\end{array}$ \\
\cline { 2 - 3 } $\begin{array}{l}\text { Serious: 5 } \\
\mathbf{( 2 . 4 1 \% )}\end{array}$ & $\begin{array}{l}\text { Not-recovered: } \\
82(39.61 \%)\end{array}$ & $\begin{array}{l}\text { Suspected drugs } \\
\text { stopped then re- } \\
\text { started: 4 (1.93\%) }\end{array}$ \\
\hline $\begin{array}{l}\text { Non-serious: } \\
\mathbf{2 0 2}(\mathbf{9 7 . 5 8 \% )}\end{array}$ & $\begin{array}{l}\text { Fatal (death): 1 } \\
(0.48 \%)\end{array}$ & $\begin{array}{l}\text { Suspected drugs } \\
\text { not stopped: } 86 \\
(41.54 \%)\end{array}$ \\
\hline
\end{tabular}

In $56.52 \%(\mathrm{n}=117)$ cases, the suspected drug was stopped completely after ADR was noticed in $1.93 \%(n=4)$ cases, the suspected drug was restarted after stopping once the symptoms subsided while in $41.54 \% \quad(n=86)$ cases the drug was not stopped and was continued after assessing the risk and benefit of the therapy as the ADR was less important than the benefit of the drug therapy for the patient (Table 3).

\section{DISCUSSION}

ADRs belong to one of the major causes of morbidity and mortality in hospital setup, but most of the cases remain below the tip of iceberg due to lack of reporting of such cases. This study was done to analyse the ADRs reported 
at $\mathrm{AMC}$, retrospectively for the pattern and type of ADRs, causative drugs, demographic profile of patients, type and severity of ADRs and their causality assessment.

A total of 207 suspected ADR reports were received from various departments at our AMC over a period of 18 months, from September 2017 to February 2019. The pattern of gender distribution of these ADRs showed that male and female patients suffering from ADRs were almost equal, male (50.25\%) and female (49.75\%), which is just coincidental finding as several other studies showed male preponderance ${ }^{12-14}$ while few studies showed female preponderance. ${ }^{15,16}$ Thus, it is concluded that gender does not influence the ADRs due to drugs. The age group affected most commonly with ADRs were in the age range of $41-50$ years $(21.25 \%)$, as found in other studies also. ${ }^{17,18}$ The age group most commonly involved also depends on the type of disease for which the patients are visiting particular hospital setup. As there are diseases which affect a particular age group and so the ADRs caused by such treatments will also affect only that particular age group of patients.

The organ system affected most commonly by ADRs was cutaneous reactions involving skin $(44.44 \%)$ followed by generalized ADRs (25.12\%) involving whole body and further followed by ADRs affecting gastrointestinal system $(9.66 \%)$. Similar patterns were also found in other studies. ${ }^{19,20}$

The commonest ADRs reported by patients were rashes, itching, whole body discomfort, chills, rigors, vomiting, abdominal pain and diarrhoea which is also similar to other studies. $^{21}$

The drugs most commonly suspected to be causing the ADRs belong to Antimicrobial agents (29.95\%). Antibiotics like Penicillin and Cephalosporins were most commonly involved. This is followed by drugs acting on central nervous system (19.80\%) like Antiepileptics and Antidepressants which is further followed by Anti-cancer drugs (11.59\%) like Paclitaxel and Rituximab. These findings are in agreement to another similar study. ${ }^{22}$ Patients given drugs by oral route were most commonly affected by ADRs (57\%) in present study followed by I.V. route $(42.51 \%)$ and I.M. route with only one case $(0.48 \%)$. According to Rawlins and Thompson classification of ADRs, 74.87\% ADRs belonged to Type A category while $25.12 \%$ ADRs were of Type B category. Majority of ADRs were non-serious (97.5\%) and only $2.41 \%$ were serious, which is similar to another study. ${ }^{22}$

Most of the patients recovered from the ADRs (59.90\%) while $39.61 \%$ patients did not recover at all and only one case $(0.48 \%)$ was fatal which led to death of the patient. In $56.52 \%$ patients, the suspected drug was stopped in $1.93 \%$ cases it was restarted again after stopping, when the symptoms of ADR subsided while in $41.54 \%$ cases the drug was not stopped at all. According to modified
Hartwig and Siegel scale, 53.62\% ADRs belonged to moderate category, $43.96 \%$ ADRs were of mild category while only $2.41 \%$ ADRs were severe. These patterns of ADRs were consistent with other similar studies. ${ }^{23,24}$

The causality of ADRs were assessed according to WHOUMC causality assessment criteria and it was found that maximum ADRs were probable (94.20\%), 2.89\% were possible while only $1.44 \%$ belonged to both certain and unlikely category. These findings were similar to a study but different from results obtained in other studies. ${ }^{25,26}$

\section{Limitations}

There are certain limitations of this study, most common being underreporting of ADRs by health care professionals (HCPs). Although we have conducted many sensitization programmes for increasing awareness among HCPs, but still under reporting remains the most important limitation of spontaneous reporting of ADRs.

Another limitation is short duration of study period because, after this duration our $\mathrm{Pv}$ associate was transferred to NCC, Ghaziabad due to some reasons. Lack of patient follow-up is another limitation.

So present results may not be generalized on large scale as the study was confined to our AMC only, still the findings will contribute to the pattern of ADRs reported in tertiary care hospitals.

\section{CONCLUSION}

This study concluded that the age group most commonly affected by ADRs was in the age range of 41-50 years with equal frequency in both male and female gender, although these may be incidental findings. Cutaneous reactions like rashes and itching were the most commonly reported ADRs and antimicrobial agents like Penicillin and Cephalosporin group of antibiotics were the most common causative drugs leading to ADRs.

Drugs administered orally were most commonly involved in causing ADRs in this study. Most of the reactions were non-serious and moderate reactions in which the patient recovered from the symptoms of ADRs after stopping the suspected drugs. Only one case was fatal which led to death of the patient. Also, most of the reactions were Type A reactions and were probable with the suspected drugs.

This study apart from its few limitations, stresses on the need of an effective and robust pharmacovigilance system for ADR monitoring and also strongly suggests that ADR reporting concepts need to be enhanced among health care professionals, to safeguard public health.

Funding: No funding sources

Conflict of interest: None declared

Ethical approval: The study was approved by Institutional Ethics Committee 


\section{REFERENCES}

1. Adverse drug reaction definition. Available at: http://www.who.int/medicines/areas/quality_safety/sa fety_efficacy/trainingcourses/definitions.pdf. Accessed on 25 January 2020.

2. Arulmani R, Rajendran SD, Suresh B. Adverse drug reaction monitoring in a secondary care hospital in South India. Br J Clin Pharmacol. 2008;65:210-6.

3. Pharmacovigilance definition. Available at: http://www.who.int/medicines/areas/quality_safety/sa fety_efficacy/pharmvigi/en/. Accessed on 25 January 2020.

4. Pharmacovigilance mission. Available at: https://ipc.gov.in//PvPI/about.html\#menu2. Accessed on 03 January 2020.

5. WHO collaborating centre for pharmacovigilance in public health programmes and regulatory services. Available at: https://www.who.int/medicines/ regulation/medicines-safety/about/collab-centresindia/en/ Accessed on 03 January 2020.

6. ADR reporting form. Available at: http://www.ipc.gov.in/PvPI/adr.html. Assessed 25 January 2020.

7. WHO causality assessment. Available at: https://www.who.int/medicines/areas/quality_safety/s afety_efficacy/WHOcausality_assessment.pdf.

Accessed on 25 January 2020.

8. Vigiflow and Signal detection. Available at: https://ipc.gov.in//PvPI/about.html\#menu2. Accessed on 25 January 2020.

9. Mahajan's Methods In Biostatistics For Medical Students And Research Workers Paperback - 25 January 2020

10. Rawlins MD, Thompson JW. Mechanisms of adverse drug reactions. In: Davies DM, ed. Textbook of adverse drug reactions. Oxford: Oxford University Press; 1991: 18-45.

11. Hartwig SC, Siegel J, Schneider PJ. Preventability and severity assessment in reporting adverse drug reactions. Am J Hosp Pharm. 1992;49(9):2229-32.

12. Lobo MG, Pinheiro SM, Castro JG, Momenté VG, Pranchevicius MC. Adverse drug reaction monitoring: Support for pharmacovigilance at a tertiary care hospital in Northern Brazil. BMC Pharmacol Toxicol. 2013;14:5.

13. Dutta SB, Beg MA, Bawa S, Anjoom M, Varma A, Singh NK. A retrospective analysis of adverse drug reactions in a tertiary care teaching hospital at Dehradun, Uttarakhand. Int J Basic Clin Pharmacol. 2015;4(1):121-4.

14. Subbanna PK, Chandy SJ. The role of active surveillance in improving the hospital adverse drug event reporting. Indian J Pharmacol. 2006;38:363-4.

15. Miller MA. Gender-based differences in the toxicity of pharmaceuticals- the food and drug Administration's perspective. Int $\mathrm{J}$ Toxicol. 2001;20(3):149-52.
16. Ramesh M, Pandit J, Parthasarathi G. Adverse drug reactions in a south Indian hospital- their severity and cost involved. Pharmacoepidemiol Drug Saf. 2003;12(8):687-92.

17. Kharb P, Mittal N, Gupta MC. An evaluation of adverse drug reactions monitoring at a pharmacovigilance unit under pharmacovigilance programme of India in a tertiary care hospital of Haryana. Int J Basic Clin Pharmacol. 2015;4:556-60.

18. Patel KJ, Kedia MS, Bajpai D, Mehta SS, Kshirsagar NA, Gogtay NJ. Evaluation of the prevalence and economic burden of adverse drug reactions presenting to the medical emergency department of a tertiary referral centre: a prospective study. BMC Clin Pharmacol. 2007; 7:8

19. Patidar D, Rajput MS, Nirmal NP, Savitri W. Implementation and evaluation of adverse drug reaction monitoring system in a tertiary care teaching hospital in Mumbai, India. Interdiscip Toxicol. 2013;6(1):41-6.

20. Jose J. Rao PG. Pattern of adverse drug reactions notified by spontaneous reporting in an Indian tertiary care teaching hospital. Pharmacol Res. 2006;54(3):226-33.

21. Caranasos GJ, Stewart RB, Cluff LE. Drug-induced illness leading to hospitalization. JAMA. 1974;228(6):713-7.

22. Sen M, Singh A, Misra M. Retrospective analysis of adverse drug reactions reported at ADR monitoring centre under PvPI in a tertiary care hospital. Int $\mathbf{J}$ Basic Clin Pharmacol. 2018;7:303-8.

23. Shareef SM, Naidu CDM, Raikar SR, Rao YV, Devika U. Development, implementation and analysis of adverse drug reaction monitoring system in a rural tertiary care teaching hospital in Narketpally, Telangana. Int J Basic Clin Pharmacol. 2015;4:757- 60.

24. Vijayakumar TM, Dhanaraju MD. Description of adverse drug reactions in a multi-speciality teaching hospital. Int J Integr Med. 2013;1(26):1-6.

25. Suh DC, Woodall BS, Shin SK, Hermes-De Santis ER. Clinical and economic impact of adverse drug reactions in hospitalized patients. Ann Pharmacother. 2000;34(12):1373-9.

26. Murphy BM, Frigo LC. Development, implementation and results of a successful multidisciplinary adverse drug reaction reporting program in a university teaching hospital. Hosp Pharm. 1993;28(12):1199-204,1240.

Cite this article as: Singh A, Jain A, Soni M, Shukla P, Lahon J, Verma AK. Pattern of adverse drug reactions reported at a tertiary care teaching hospital in northern India. Int J Basic Clin Pharmacol 2020;9:625-32. 